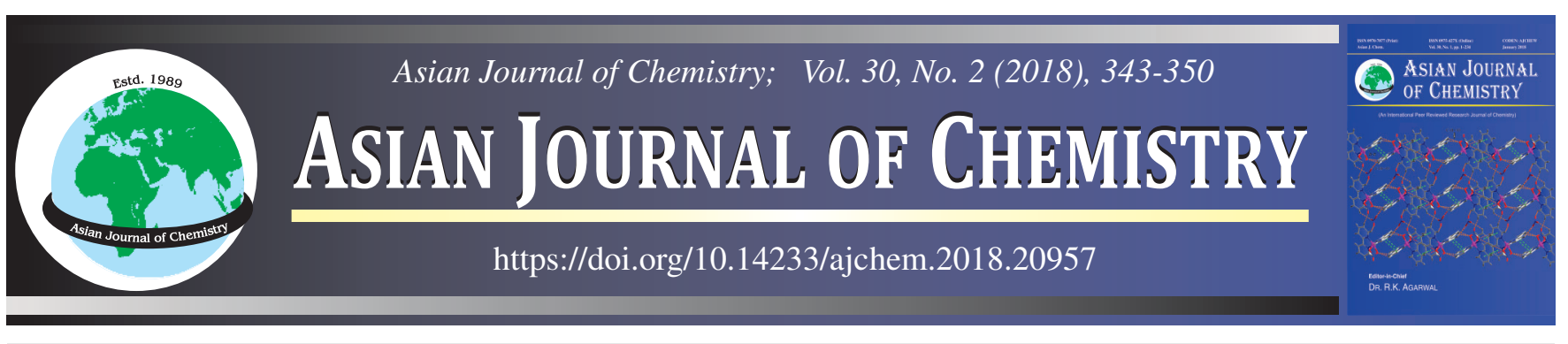

\title{
Growth, Spectral, Thermal, Linear and Non-Linear Optical Characteristics of an Efficient Organic Crystal: L-Lysinium 5-Sulfosalicylate
}

\author{
R. Usha, N. Hema, V. Revathi Ambika, D. Shalini and D. Jayalakshmi*
}

PG \& Research Department of Physics, Queen Mary's College, Chennai-600 004, India

*Corresponding author: E-mail: djayalakshmi2016@gmail.com

\begin{abstract}
L-Lysinium 5-sulfosalicylate (LL5SS) has been synthesized and grown by solution growth method at room temperature using deionized water as a solvent. The crystal structure of the materials was solved by single crystal X-ray diffraction analysis and it was found that the material has monoclinic system with the space group $\mathrm{P} 2_{1}$. Fourier transform infrared spectral study was carried out to confirm functional groups present in the crystal. The optical absorption study shows that the crystal is transparent in the entire visible region with a cut-off wavelength of $324 \mathrm{~nm}$. Photoluminescence studies were also carried out to identify the excitation emission of the grown LL5SS crystal. Dielectric study was performed on the single crystal to study the power dissipation of the material in the presence of alternating electric field. Thermal stability has been assessed by thermo gravimetric analysis. Mechanical parameters were calculated. The laser damage threshold value of LL5SS crystal was estimated to be $5.6 \mathrm{GW} / \mathrm{cm}^{2}$ using a Nd:YAG laser. The Kurtz and Perry powder SHG efficiencies were measured. Non-linear refractive index $\left(\mathrm{n}_{2}\right)$, non-linear absorption coefficient $(\beta)$ and third-order non-linear optical susceptibility $\left(\chi^{3}\right)$ values of LL5SS were found from $\mathrm{Z}$ scan technique.
\end{abstract}

Keywords: Single crystal XRD, Photoluminesence, Dielectric measurement, Third order non-linear optical property, Micro hardness.

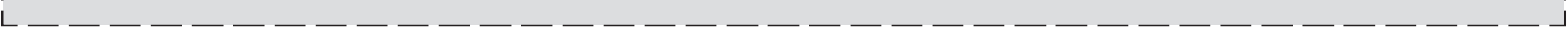

\section{INTRODUCTION}

Nowadays, much consideration was provided to the nonlinear optical materials, which are the main focus of many research works going on around the world. The role of organic non-linear optical (NLO) materials with large optical nonlinearity in the fabrication of devices in telecommunication, optical information processing and high optical disk data storage is immensely significant [1-7]. Organic materials are the prime choice of researchers because they have tendency to show higher order of non-linearity. The laser beam interacts with the delocalized $\pi$-electrons existing in the organic molecule produce non-linear polarization. The non-linear susceptibility of an organic material would be larger when it has donor-acceptor conjugated molecular systems. Normally amino acids have the tendency to crystallize in a non-centrosymmetric form which is useful for non-linear optical applications. A sequence of second order/third order NLO active materials composed of L-Lysine have been synthesized, such as, L-lysinium picrate, L-Lysine adipate, L-lysine acetate, tetra L-Lysine alanine mono hydrochloride dehydrate [8-11]. From the coordination chemistry, 5-sulfosalicylicacid (5SSA) is especially an attractive ligand, possessing three potential coordination groups such as $\mathrm{OH}, \mathrm{COOH}$ and $\mathrm{SO}_{3} \mathrm{H}$ [12-15].
In this work, the single crystal of L-lysinium 5-sulfosalicylate (LL5SS), an organic NLO compound has been synthesized by slow evaporation method in aqueous solution at room temperature. In this work, the structural, optical, dielectric, hardness, photoluminescence, laser threshold damage, second and third order non linearity characterization of LL5SS are reported.

\section{EXPERIMENTAL}

Synthesis: The high purity L-Lysine monohydrochloride was mixed with 5-sulfosalicylic acid in the molar ratio of 1:1 and it was dissolved in deionized water. The chemical reaction scheme is given in Fig. 1. The solution was stirred well using magnetic stirrer for about $5 \mathrm{~h}$ at $40{ }^{\circ} \mathrm{C}$ and it was filtered using Whatman filter paper and kept for evaporation in a constant temperature bath (CTB). The purity of the LL5SS salt was enhanced by recrystalizing the salt four times. Colourless needle shaped crystals of LL5SS having a typical size of $12 \mathrm{~mm}$ $\times 5 \mathrm{~mm} \times 2 \mathrm{~mm}$ were collected in 20 days and the photograph of grown crystal is presented in Fig. 2.

Solubility: Solubility of a material in a particular solvent defines the super saturation which is the driving force for the rate of crystal growth. The solubility data were determined by 


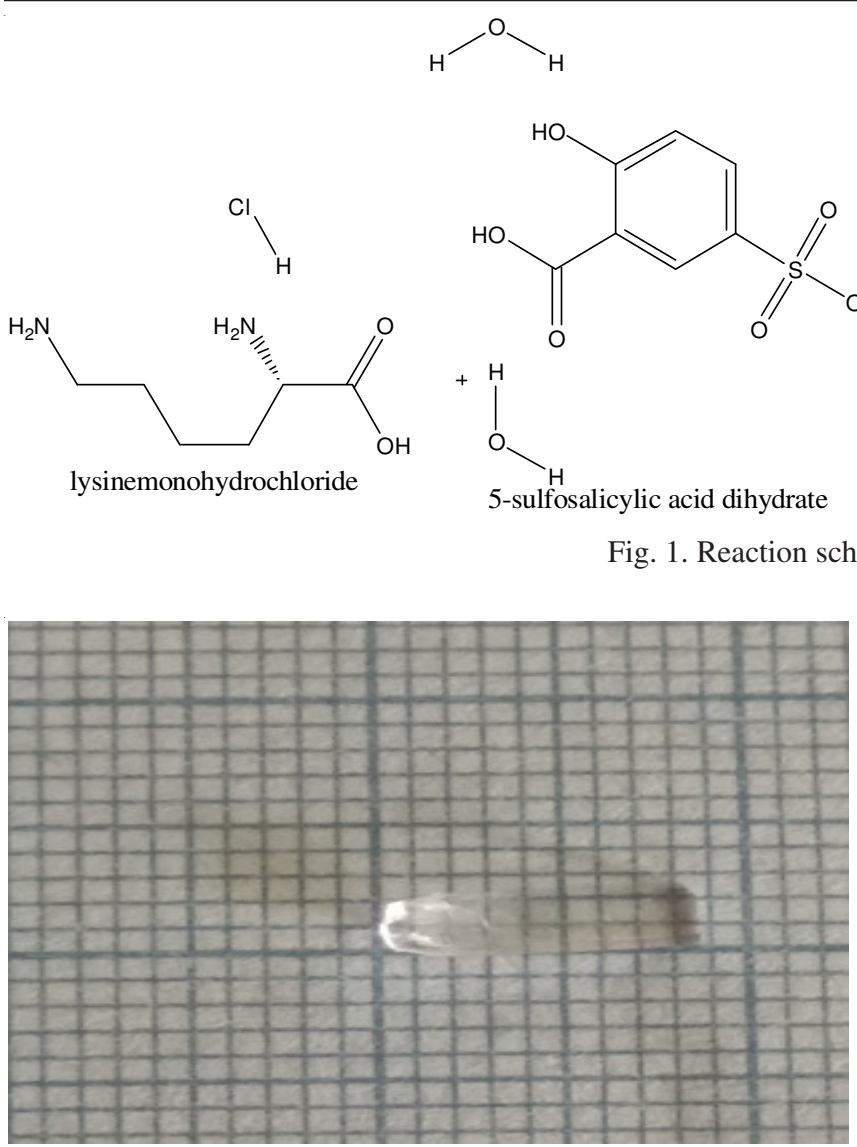

Fig. 2. As-grown crystal of LL5SS

dissolving the synthesized salt of LL5SS in $100 \mathrm{~mL}$ solvent at a constant temperature with continuous stirring. After attaining saturation, the equilibrium concentration of the solute was analyzed gravimetrically. The solubility of LL5SS has been determined for different temperatures, 30,40 and $50{ }^{\circ} \mathrm{C}$, respectively as shown in Fig. 3.

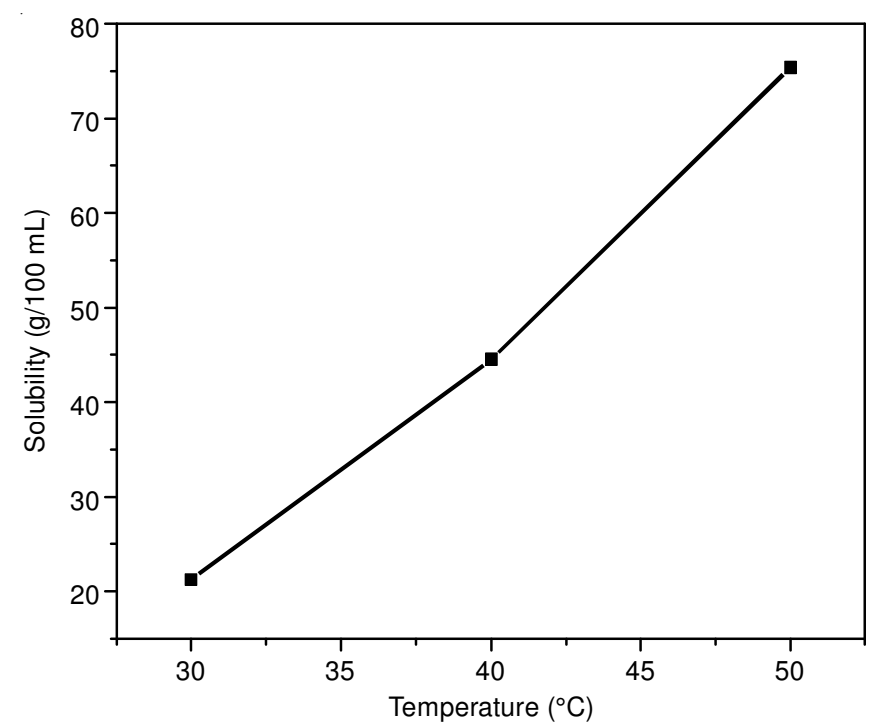

Fig. 3. Solubility curve of LL5SS in water

\section{RESULTS AND DISCUSSION}

Single crystal X-ray diffraction studies: The single crystal $\mathrm{X}$-ray diffraction studies have been carried out to confirm the crystallinity and to determine the lattice parameters of the grown sample. The single crystal of LL5SS with dimensions $0.250 \mathrm{~mm} \times 0.220 \mathrm{~mm} \times 0.120 \mathrm{~mm}$ was chosen for X-ray diffraction study. The structure of LL5SS was solved by the direct method using SHELXL-2014/7 fined by the full-matrix least squares methods on $\mathrm{F}^{2}$. A Bruker kappa APEXII single crystal X-ray Diffractometer with $\operatorname{MoK}_{\alpha}(\lambda=0.71073 \AA$ A radiation was used for $\mathrm{X}$-ray diffraction study. The calculated lattice parameter values are $\mathrm{a}=6.8770 \AA \mathrm{A}, \mathrm{b}=16.4266 \AA$, $\mathrm{c}=$ $11.9729 \AA$ and $\mathrm{V}=1351.39 \mathrm{~A}^{3}$. LL5SS crystallizes in monoclinic system with noncentro symmetric space group $\mathrm{P} 2{ }_{1}$. The crystal data and the structure refinement for LL5SS material is given in Table-1. The ORTEP diagram of the grown LL5SS single crystal is shown in Fig. 4. The structure was solved using collected/unique reflections $10406 / 4681$ [R(int) $=0.0177]$. The

TABLE-1

CRYSTAL DATA AND STRUCTURE REFINEMENT FOR LL5SS

\begin{tabular}{ll}
\hline Identification code & $\mathrm{L} 5 \mathrm{SS}$ \\
Empirical formula & $\mathrm{C}_{20} \mathrm{H}_{30} \mathrm{~N}_{2} \mathrm{O}_{17} \mathrm{~S}_{2}$ \\
Formula weight & 634.58 \\
Temperature & $296(2) \mathrm{K}$ \\
Wavelength & $0.71073 \mathrm{~A}$ \\
Crystal system, space group & Monoclinic, $\mathrm{P}_{1}$ \\
Unit cell dimensions & $\mathrm{a}=6.8770(2) \AA \AA \alpha=90^{\circ}$ \\
& $\mathrm{b}=16.4266(4) \AA ; \beta=92.3535(14)^{\circ}$ \\
& $\mathrm{c}=11.9729(3) \AA ; \gamma=90^{\circ}$ \\
Volume & $1351.39(6) \AA^{3}$ \\
Z, Calculated density & $2,1.559 \mathrm{Mg} / \mathrm{m}^{3}$ \\
Absorption coefficient & $0.282 \mathrm{~mm}{ }^{-1}$ \\
F(000) & 664 \\
Crystal size & $0.250 \times 0.220 \times 0.120 \mathrm{~mm}$ \\
Theta range for data collection & 1.702 to $25.000^{\circ}$ \\
Limiting indices & $-7<=\mathrm{h}<=8,-19<=\mathrm{k}<=19$, \\
& $-14<=1<=14$ \\
Reflections collected/unique & $10406 / 4681[\mathrm{R}(\mathrm{int})=0.0177]$ \\
Completeness to theta $=25.000^{\circ}$ & $100.0 \%$ \\
Absorption correction & None \\
Refinement method & Full-matrix least-squares on $\mathrm{F}^{2}$ \\
Data/restraints/parameters & $4681 / 2 / 427$ \\
Goodness-of-fit on $\mathrm{F}^{2}$ & 1.070 \\
Final R indices [I $2 \sigma(\mathrm{I})]$ & $\mathrm{R} 1=0.0270, \mathrm{wR} 2=0.0679$ \\
R indices $($ all data) & $\mathrm{R} 1=0.0284, \mathrm{wR} 2=0.0688$ \\
Absolute structure parameter & $0.006(18)$ \\
Extinction coefficient & $\mathrm{n} / \mathrm{a}$ \\
Largest diff. peak and hole & 0.273 and $-0.365 \mathrm{e} . \mathrm{A}^{-3}$ \\
CCDC & 1562492 \\
\hline &
\end{tabular}




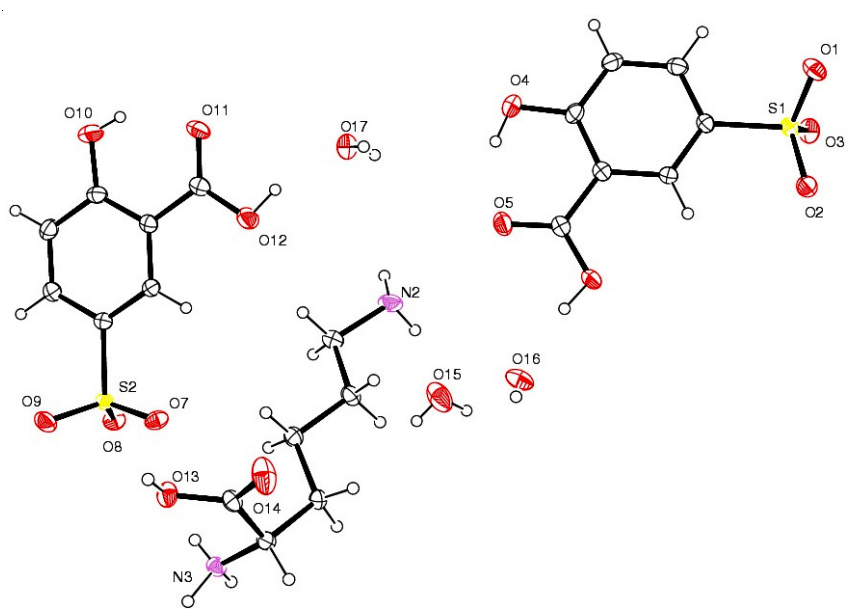

Fig. 4. ORTEP diagram of LL5SS

goodness-of-fit was 1.066. The crystallographic data (CIF) for the molecule compound structure reported in this paper have been deposited in the Cambridge Crystallographic Data Centre as supplementary material number CCDC 1562492.The bond length is given in Table-2. Hydrogen bond distances and angles given in Table-3.

Fourier transform infrared spectroscopy analysis: FTIR spectroscopy is an important tool to identify the presence of various functional group and the types of vibration in the

\begin{tabular}{|c|c|c|c|}
\hline \multicolumn{4}{|c|}{$\begin{array}{c}\text { TABLE-2 } \\
\text { BOND LENGTHS }(\AA) \text { FOR LL5SS }\end{array}$} \\
\hline C1-C6 & $1.375(4)$ & $\mathrm{C} 1-\mathrm{C} 2$ & $1.392(4)$ \\
\hline C1-S1 & $1.772(3)$ & $\mathrm{C} 2-\mathrm{C} 3$ & $1.381(4)$ \\
\hline $\mathrm{C} 2-\mathrm{H} 2$ & 0.93 & C3-C4 & $1.386(5)$ \\
\hline $\mathrm{C} 3-\mathrm{H} 3$ & 0.93 & $\mathrm{C} 4-\mathrm{O} 4$ & $1.352(4)$ \\
\hline C4-C5 & $1.409(4)$ & C5-C6 & $1.403(4)$ \\
\hline C5-C7 & $1.475(4)$ & C6-H6 & 0.93 \\
\hline C7-O5 & $1.224(4)$ & C7-O6 & $1.312(4)$ \\
\hline C8-C9 & $1.371(4)$ & C8-C13 & $1.397(4)$ \\
\hline $\mathrm{C} 8-\mathrm{S} 2$ & $1.765(3)$ & C9-C10 & $1.399(4)$ \\
\hline C9-H9 & 0.93 & $\mathrm{C} 10-\mathrm{C} 11$ & $1.395(4)$ \\
\hline $\mathrm{C} 10-\mathrm{C} 14$ & $1.471(4)$ & C11-O10 & $1.349(4)$ \\
\hline $\mathrm{C} 11-\mathrm{C} 12$ & $1.398(5)$ & C12-C13 & $1.376(4)$ \\
\hline C12-H12 & 0.93 & C13-H13 & 0.93 \\
\hline C14-O11 & $1.220(4)$ & C14-O12 & $1.323(4)$ \\
\hline C15-N2 & $1.491(4)$ & C15-C16 & $1.505(4)$ \\
\hline C15-H15A & 0.97 & C15-H15B & 0.97 \\
\hline C16-C17 & $1.528(4)$ & C16-H16A & 0.97 \\
\hline C16-H16B & 0.97 & C17-C18 & $1.525(4)$ \\
\hline C17-H17A & 0.97 & C17-H17B & 0.97 \\
\hline C18-C19 & $1.521(4)$ & $\mathrm{C} 18-\mathrm{H} 18 \mathrm{~A}$ & 0.97 \\
\hline C18-H18B & 0.97 & C19-N3 & $1.476(4)$ \\
\hline C19-C20 & $1.520(4)$ & C19-H19 & 0.98 \\
\hline $\mathrm{C} 20-\mathrm{O} 14$ & $1.200(4)$ & C20-O13 & $1.308(4)$ \\
\hline N2-H4N & $1.00(4)$ & N2-H5N & $0.90(4)$ \\
\hline N2-H6N & $0.84(5)$ & $\mathrm{N} 3-\mathrm{H} 2 \mathrm{~N}$ & $0.93(4)$ \\
\hline N3-H1N & $0.74(4)$ & N3-H3N & $0.98(4)$ \\
\hline O1-S1 & $1.451(2)$ & $\mathrm{O} 2-\mathrm{S} 1$ & $1.461(2)$ \\
\hline O3-S1 & $1.454(2)$ & O4-H8O & $0.86(5)$ \\
\hline O6-H1O & $0.89(4)$ & $\mathrm{O} 7-\mathrm{S} 2$ & $1.468(2)$ \\
\hline O8-S2 & $1.449(2)$ & O9-S2 & $1.448(2)$ \\
\hline O10-H10 & 0.82 & $\mathrm{O} 12-\mathrm{H} 2 \mathrm{O}$ & $0.90(3)$ \\
\hline O13-H5O & $0.73(4)$ & $\mathrm{O} 15-\mathrm{H} 4 \mathrm{O}$ & $0.82(5)$ \\
\hline O15-H3O & $0.77(6)$ & O16-H9O & $0.62(3)$ \\
\hline O17-H7O & $0.87(4)$ & O17-H6O & $0.75(4)$ \\
\hline
\end{tabular}

TABLE-3

HYDROGEN BOND DISTANCES ( $\AA$ ) AND ANGLES $\left({ }^{\circ}\right)$ FOR LL5SS

\begin{tabular}{|c|c|c|c|c|}
\hline & Donor-H & $\begin{array}{c}\text { Acceptor- } \\
\text { H }\end{array}$ & $\begin{array}{l}\text { Donor- } \\
\text { Acceptor }\end{array}$ & Angle \\
\hline 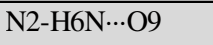 & $0.84(5)$ & $2.23(5)$ & $2.895(4)$ & 136.(4) \\
\hline $\mathrm{N} 2-6 \mathrm{~N} \cdots \mathrm{O} 5$ & $0.84(5)$ & $2.45(5)$ & $2.958(4)$ & $120 .(4)$ \\
\hline $\mathrm{O} 4-8 \mathrm{O} \cdots \mathrm{O} 5$ & $0.86(5)$ & $1.83(5)$ & $2.604(4)$ & $150 .(4)$ \\
\hline $\mathrm{O} 12 \mathrm{H} 2 \mathrm{O} \cdots \mathrm{O} 17$ & $0.90(3)$ & $1.84(3)$ & $2.704(3)$ & $160 .(6)$ \\
\hline 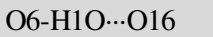 & $0.89(4)$ & $1.71(4)$ & $2.588(3)$ & 168.(3) \\
\hline 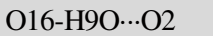 & $0.62(3)$ & $2.19(4)$ & $2.810(4)$ & 173.(4) \\
\hline 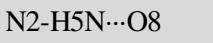 & $0.90(4)$ & 2.13(4) & $2.961(4)$ & 154.(3) \\
\hline N2-H4N‥O15 & $1.00(4)$ & $1.83(4)$ & $2.790(4)$ & 162.(4) \\
\hline N3-H3N‥O11 & $0.98(4)$ & $2.20(4)$ & $2.848(4)$ & 122.(3) \\
\hline N3-H3N …O3 & $0.98(4)$ & 2.01(4) & $2.853(4)$ & 143.(3) \\
\hline N3-H1N‥O17 & $0.74(4)$ & $2.20(4)$ & $2.905(4)$ & 162.(4) \\
\hline N3-H2N …O1 & $0.93(4)$ & $1.91(4)$ & $2.791(4)$ & 157.(3) \\
\hline O17-H6O $\cdots \mathrm{O} 8$ & $0.75(4)$ & $2.19(4)$ & $2.859(3)$ & 148.(4) \\
\hline 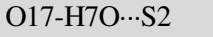 & $0.87(4)$ & $2.82(4)$ & $3.667(3)$ & 162.(4) \\
\hline O17-H7O $\cdots$ O9 & $0.87(4)$ & 2.67(4) & $3.321(4)$ & 133.(4) \\
\hline O17-H7O $\cdots \mathrm{O} 7$ & $0.87(4)$ & $2.04(4)$ & $2.887(3)$ & 164.(4) \\
\hline $\mathrm{O} 13-\mathrm{H} 5 \mathrm{O} \cdots \mathrm{S} 2$ & $0.73(4)$ & $2.89(4)$ & $3.427(2)$ & 132.(3) \\
\hline O13-H5O $\cdots \mathrm{O} 7$ & $0.73(4)$ & $1.95(4)$ & $2.652(3)$ & 159.(4) \\
\hline $\mathrm{O} 15-\mathrm{H} 3 \mathrm{O} \cdots \mathrm{O} 14$ & $0.77(6)$ & $2.14(6)$ & $2.865(4)$ & 158.(6) \\
\hline $\mathrm{O} 15-\mathrm{H} 4 \mathrm{O} \cdots \mathrm{S} 1$ & $0.82(5)$ & $2.81(5)$ & $3.570(3)$ & 154.(4) \\
\hline $\mathrm{O} 15-\mathrm{H} 4 \mathrm{O} \cdots \mathrm{O} 3$ & $0.82(5)$ & $2.63(5)$ & $3.157(4)$ & 124.(4) \\
\hline $\mathrm{O} 15-\mathrm{H} 4 \mathrm{O} \cdots \mathrm{O} 2$ & $0.82(5)$ & $2.05(5)$ & $2.870(4)$ & $175 .(4)$ \\
\hline O10-H10‥O11 & 0.82 & 1.89 & $2.598(3)$ & 144.5 \\
\hline С19-H19...O6 & 0.98 & 2.59 & $3.330(3)$ & 132.5 \\
\hline C15-H15A-.O14 & 0.97 & 2.61 & $3.315(4)$ & 129.4 \\
\hline $\mathrm{C} 2-\mathrm{H} 2 \cdots \mathrm{O} 13$ & 0.93 & 2.6 & $3.480(4)$ & 158.6 \\
\hline
\end{tabular}

material. FTIR transmission spectrum of LL5SS crystal was recorded in the region $4000-400 \mathrm{~cm}^{-1}$ employing a Perkin Elmer spectrometer by $\mathrm{KBr}$ pellet method is shown in Fig. 5. The frequency assignment for LL5SS with various functional groups is presented in Table-4. The peak observed at 3522 $\mathrm{cm}^{-1}$ is assigned to $\mathrm{NH}$ stretching vibration. The broad peak at $3094 \mathrm{~cm}^{-1}$ is due to the presence of water molecule in the crystal. The vibrational band at $1741 \mathrm{~cm}^{-1}$ is due to the $\mathrm{C}=\mathrm{O}$ stretching vibration. The asymmetric and symmetric bending vibrations are observed at 1611 and $1517 \mathrm{~cm}^{-1}$. The peaks at $1497 \mathrm{~cm}^{-1}$ and $1474 \mathrm{~cm}^{-1}$ are attributed to $\mathrm{CH}$ scissoring and wagging. The bending vibrations of $\mathrm{OH}$ group are observed at $1440 \mathrm{~cm}^{-1}$. The peaks at about 1328 and $1024 \mathrm{~cm}^{-1}$ assigned for $\mathrm{CN}$ stretching vibrations. The $\mathrm{CO}$ stretching vibration band appeared at $1290 \mathrm{~cm}^{-1}$. The peak with wave number at 1161 $\mathrm{cm}^{-1}$ was observed for the rocking $\mathrm{NH}_{3}$ structure. The band at $910 \mathrm{~cm}^{-1}$ is due to the $\mathrm{CC}$ stretching vibration. The sharp peak at $841 \mathrm{~cm}^{-1}$ is due to the out of plane bending vibration of hydrogen bonds. The $\mathrm{CH}$ bending vibration and $\mathrm{CS}$ stretching vibrations absorbed at 819 and $793 \mathrm{~cm}^{-1}$. The $\mathrm{COO}^{-}$scissoring, $\mathrm{SO}_{2}$ scissoring, $\mathrm{SO}_{2}$ wagging vibrations are positioned at $711,588,529 \mathrm{~cm}^{-1}$ respectively. This observation confirms the formation of LL5SS compound.

UV-visible spectroscopy: The optical property of the LL5SS compound has been assessed by using LAMBDA-35 UV spectrometer in the wavelength range of $200-800 \mathrm{~nm}$. The UV-visible studies give structural information. Absorption of UV and visible light involves promotion of the electrons in $\pi$ and $\sigma$ orbitals from the ground state to higher energy states. Lower UV cut off wavelength plays an important role in identifying 


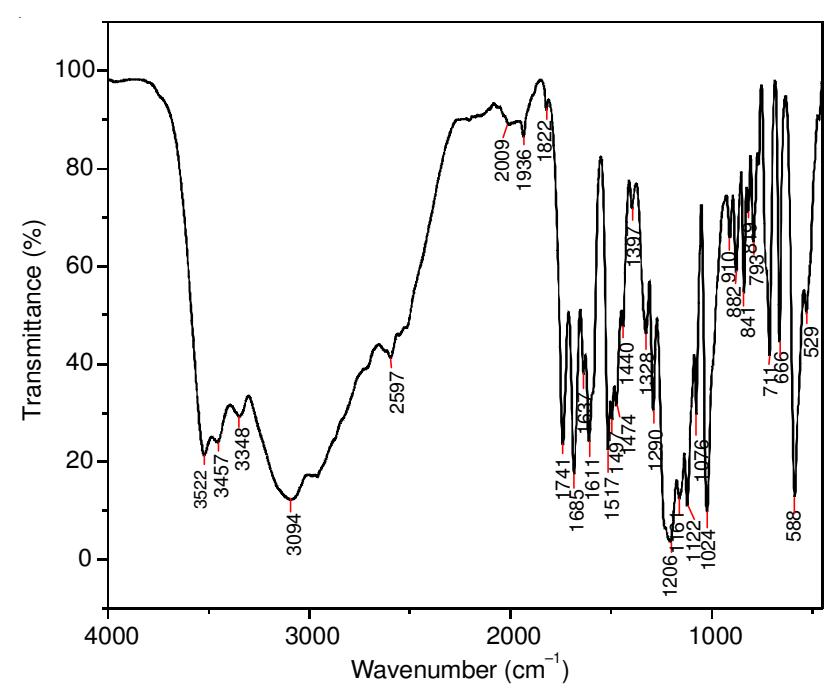

Fig. 5. FTIR spectrum of LL5SS

\begin{tabular}{|c|c|}
\hline \multicolumn{2}{|c|}{$\begin{array}{c}\text { TABLE-4 } \\
\text { FT-IR ASSIGNMENTS OF LL5SS }\end{array}$} \\
\hline Wavenumber $\left(\mathrm{cm}^{-1}\right)$ & Assignments \\
\hline 3522 & $\mathrm{NH}_{3}{ }^{+}$symmetric stretching \\
\hline 3094 & $\mathrm{OH}$ stretching vibration \\
\hline 1685 & $\mathrm{C}=\mathrm{O}$ stretching frequency of $\mathrm{COOH}$ \\
\hline 1611 & $\mathrm{NH}_{3}{ }^{+}$Asymmetric bending vibration \\
\hline 1517 & $\mathrm{NH}_{3}{ }^{+}$Symmetric bending vibration \\
\hline 1290 & C-O Stretching vibration \\
\hline 1161 & Rocking of $\mathrm{NH}_{3}^{+}$ \\
\hline 910 & C-C Stretching vibration \\
\hline 711 & $\mathrm{COO}^{-}$scissoring \\
\hline 588 & $\mathrm{SO}_{2}$ scissoring \\
\hline 529 & $\mathrm{SO}_{2}$ Wagging \\
\hline
\end{tabular}

the potential of an NLO material. The lower cut off wavelength of the crystal is found to be $324 \mathrm{~nm}$ and there is no absorption of light to any appreciable extent in the visible range of the electromagnetic spectrum [16]. The optical band gap of LL5SS crystal was determined using Tauc's extrapolation method as depicted in Fig. 6. The optical band gap of LL5SS is found to be 3.536 $\mathrm{eV}$. The large value of band gap indicates that the crystal can be suitable material for the optoelectronics and NLO applications.

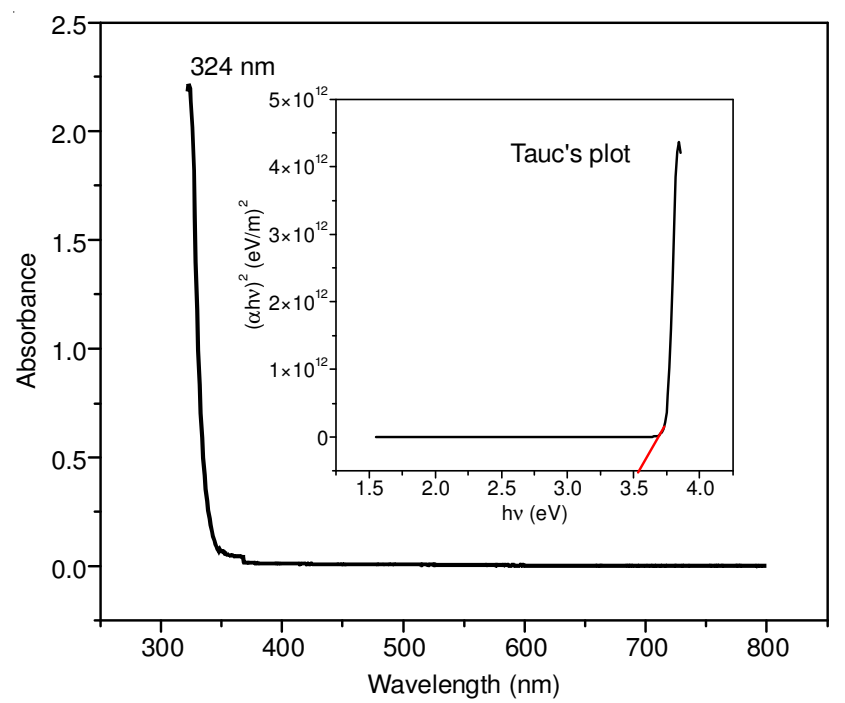

Fig. 6. Optical Absorption spectrum of LL5SS single crystal along with its Tauc plot (as inset)
Photoluminescence properties: The photoluminescence technique is the accurate method for determining the optical quality as well as its excitation fine structure [17]. The photoluminescence spectrum was recorded using a Perkin Elmer photoluminescence unit at room temperature with slit width $10 \mathrm{~nm}$ in the range of $350-650 \mathrm{~nm}$. The LL5SS was excited at $324 \mathrm{~nm}$ and the emission spectrum was obtained as shown in Fig. 7. The strong luminescence broad peak at $432 \mathrm{~nm}$ was observed and is due to intermolecular interactions of lattice vibrations and indicates that the grown crystal has a violet fluorescence emission. This property of having strong emission in this range may lead to potential application of this material in optoelectronic devices [18]. The materials with photoluminescence of violet and deep red are found to be more useful for OLED applications and optical data storage applications [19]. Hence the broad luminescence profile gives information about the electronic property of the grown crystal.

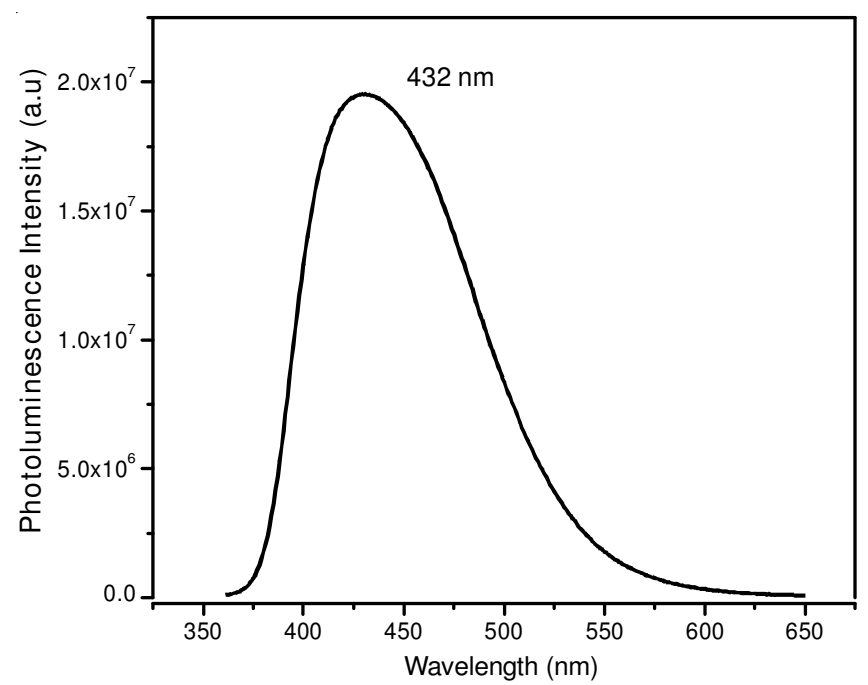

Fig. 7. Photoluminescence spectrum of the LL5SS crystal excited at $432 \mathrm{~nm}$

Thermal analysis: Thermogravimetric analysis and differential thermal analysis gives information about the phase transition and various stages of decomposition of the crystal. Thermal analyses (TG/DTA) were performed by a Instrument: TGA Q500 V20.10 Build 36 and the spectrum is shown in Fig. 8. The three major exothermic peaks were observed at 118.4 , 242.5 and $559.2^{\circ} \mathrm{C}$ due to the major decomposition of material in the DTA curve. From the TG curve, it is observed that there was $7.8 \%$ of weight loss around at $97.4{ }^{\circ} \mathrm{C}$. This confirms the removal of water molecule in the sample. In the second stage of decomposition, sulfosalicylates, $\mathrm{CO}_{2}$ and $\mathrm{CH}_{4}$ get liberated with the weight loss of $65.87 \%$ of the material [20]. Third stage of weight loss is due to the release of $\mathrm{NH}_{3}$. Hence, the LL5SS material has reasonably good thermal stability which satisfies the requirement for the device fabrication.

Dielectric measurement: The dielectric measurements were carried out on the grown LL5SS single crystal with respect to the temperature and frequency. The well polished and good quality single crystal was subjected to dielectric measurements by using Numetriq PSM1735 equipped with resistive furnace and that is connected with a temperature controller (Eurotherm model No. 2404 with the accuracy of $\pm 1{ }^{\circ} \mathrm{C}$ ). The dielectric 


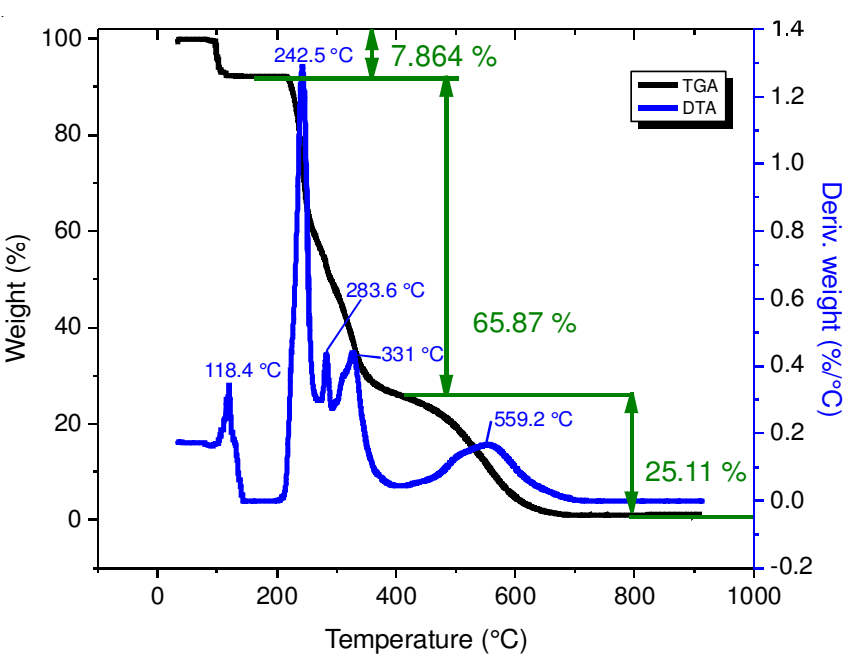

Fig. 8. TGA-DTA curve of LL5SS

constant $\varepsilon_{\mathrm{r}}$ indicates the ability of the dielectric to polarize and it can be defined as the ratio of the dielectric's permittivity to the permittivity of a vacuum:

$$
\varepsilon_{\mathrm{r}}=\mathrm{Ct} / \mathrm{A} \varepsilon_{0}
$$

where $\mathrm{A}$ is the area of the plate, $\mathrm{d}$ is the distance between the two parallel plates. $\varepsilon_{0}$ is the absolute permittivity of the free space. The frequency dependence of the dielectric constant $(\varepsilon)$ is shown in Fig. 9.

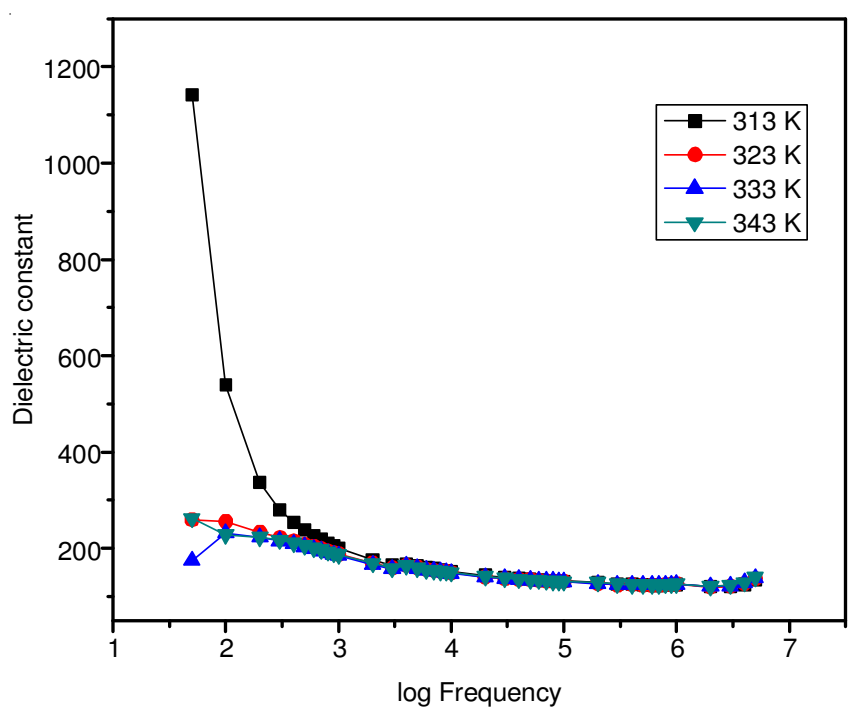

Fig. 9. Plot of $\log \mathrm{f}$ versus dielectric constant for LL5SS crystal

The dielectric constant has high values in the lower frequency region and then it decreases with increasing the frequency. The high value of dielectric constant at low frequency may be due to the orientation, space charge, electronic and ionic polarization [21]. The increase in temperature leads to increase in dielectric constant and is due to the presence of electronic polarization. Dielectric loss is the absorption of energy by movement of charges in an alternating field and is particularly high around the relaxation and resonance frequencies of the polarization mechanisms. It is observed that the dielectric loss decreases with increasing frequency. The frequency dependence of the dielectric loss $(\varepsilon)$ is shown in Fig. 10. The low dielectric loss at high frequencies indicates that the LL5SS possess enhanced optical quality with lesser defects and it is suitable for NLO application.

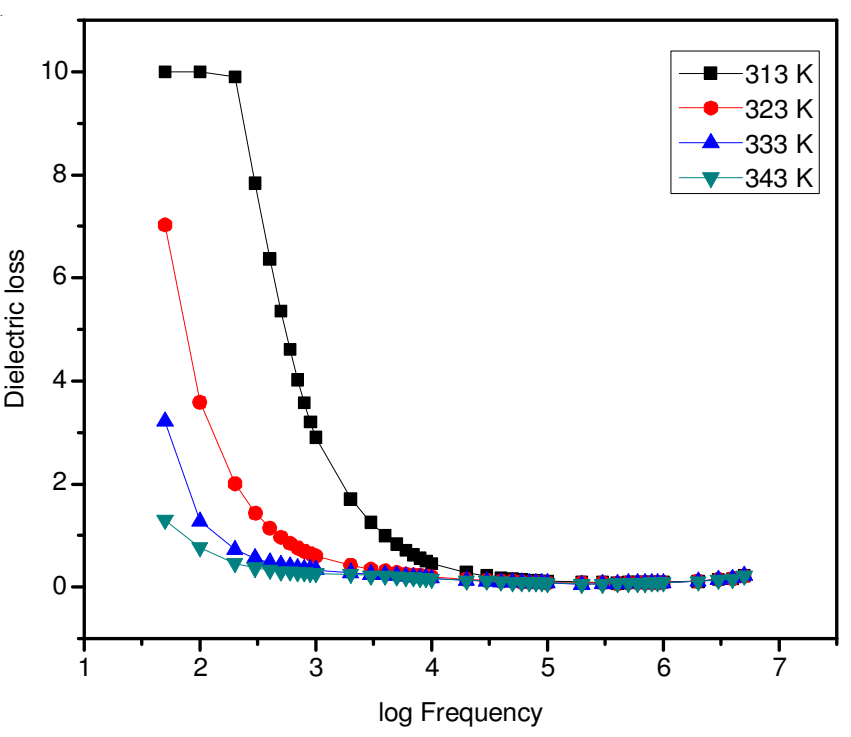

Fig. 10. Plot of $\log \mathrm{f}$ versus dielectric loss for LL5SS crystal

\section{Non-linear optical (NLO) studies}

Second-order non-linear optical property: A high intensity $\mathrm{Nd}$ :YAG laser $(\lambda=1064 \mathrm{~nm})$ with a pulse duration of $6 \mathrm{~ns}$ was passed through the powdered sample. The second harmonic signal produced in LL5SS was verified from the green light $(\lambda=532 \mathrm{~nm})$ emission from the crystal. It is observed that the SHG efficiency of the grown single crystal is 0.87 times that of the standard KDP crystal

Third order non-linear optical property: Z-scan approach is a standard method for the precise assessment of intensity dependent non-linear refractive index $\mathrm{n}_{2}$, non-linear absorption coefficient $\beta$ and non-linear susceptibilities. OBIS CW laser of wavelength of $640 \mathrm{~nm}$ was used in this experiment. In the $\mathrm{Z}$-scan technique a stepper motor was used to move a crystal sample across the $+\mathrm{Z}$ to $-\mathrm{Z}$ axial direction and thus the crystal sample will experience different light intensity at its various positions. The transmission of the beam through an aperture placed in the far field is measured using a photo detector fed to the digital power meter. Using the collected data of Z-scan, the difference between the normalized valley and peak transmittance $\Delta \mathrm{Tp}-\mathrm{v}$ can be calculated by

$$
\Delta \mathrm{T}_{\mathrm{P}-\mathrm{V}}=0.46(1-\mathrm{S})^{0.25}|\Delta \Phi|
$$

where $|\Delta \Phi|$ is on axis phase shift at the focus, $S$ is the aperture linear transmittance and it can be calculated by

$$
S=1-\exp \left(\frac{-2 r_{a}^{2}}{\omega_{a}^{2}}\right)
$$

where $r_{a}$ is the radius of the aperture and $\omega_{a}$ is the beam radius at the aperture.

$\mathrm{L}_{\mathrm{eff}}$ is the effective thickness of the sample measured from

$$
\mathrm{L}_{\mathrm{eff}}=\frac{[1-\exp (-\alpha \mathrm{L})]}{\propto}
$$


where $\mathrm{L}$ is the thickness of the sample and $\mathrm{a}$ is the linear absorption coefficient. The value of non-linear refractive index $\left(\mathrm{n}_{2}\right)$ can be measured using the relation:

$$
\mathrm{n}_{2}=\frac{\Delta \Phi}{\mathrm{KI}_{0} \mathrm{~L}_{\text {eff }}}
$$

where $\mathrm{K}$ is the wavenumber $(2 \pi / \lambda)$. The real parts of the third order non-linear susceptibility $\left[\chi^{3}\right]$ is determined by non-linear refractive index $\mathrm{n}_{2}$ collected from the closed aperture Z-scan data employing the relation:

$$
\operatorname{Re} \chi^{(3)}=\frac{10^{-4}\left(\varepsilon_{0} C^{2} n_{0}^{2} n_{2}\right)}{\pi}\left(\frac{\mathrm{cm}^{2}}{\mathrm{~W}}\right)
$$

The value the non-linear absorption coefficient $\beta$ can be estimated from open aperture curve using the expression:

$$
\beta=\frac{2 \sqrt{2} \Delta \mathrm{T}}{\mathrm{I}_{0} \mathrm{~L}_{\text {eff }}}
$$

The imaginary parts of the third order non-linear susceptibility $\left[\chi^{3}\right]$ is determined by the non-linear absorption coefficient $\beta$ employing the relation:

$$
\operatorname{Im} \chi^{(3)}=\frac{10^{-2}\left(\varepsilon_{0} C^{2} n_{0}^{2} \lambda \beta\right)}{4 \pi}\left(\frac{\mathrm{cm}}{W}\right)
$$

The third-order non-linear optical susceptibility is thus obtained by:

$$
\chi^{3}=\sqrt{\operatorname{Re}\left(\chi^{3}\right)^{2}+\operatorname{Im}\left(\chi^{3}\right)^{2}}
$$

Fig. 11 shows the normalized transmittance for the open aperture (OA) curve of LL5SS and the transmission is minimum at the focal point This indicates that the materials exhibit two-photon absorption (TPA).

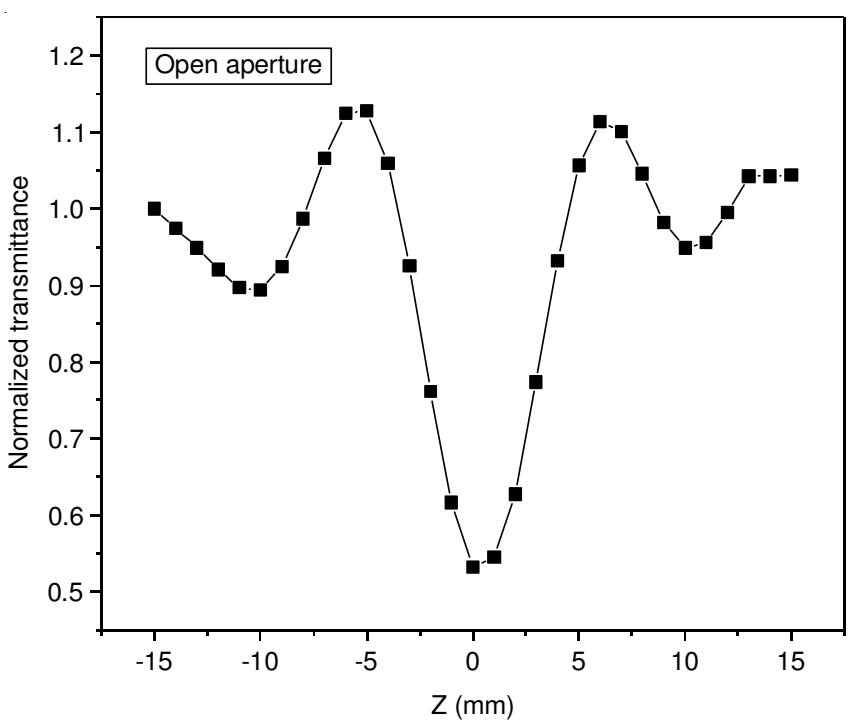

Fig. 11. Z-scan curve of LL5SS in open aperture

Fig. 12 shows the normalized transmittance for the closed aperture curve of LL5SS. The valley to peak configuration of the curve shows that the refractive index changes is positive, exhibiting a self-focusing effect. From the closed aperture curve, the pre-focal transmittance valley is followed by the post focal peak which is the signature of positive non-linearity

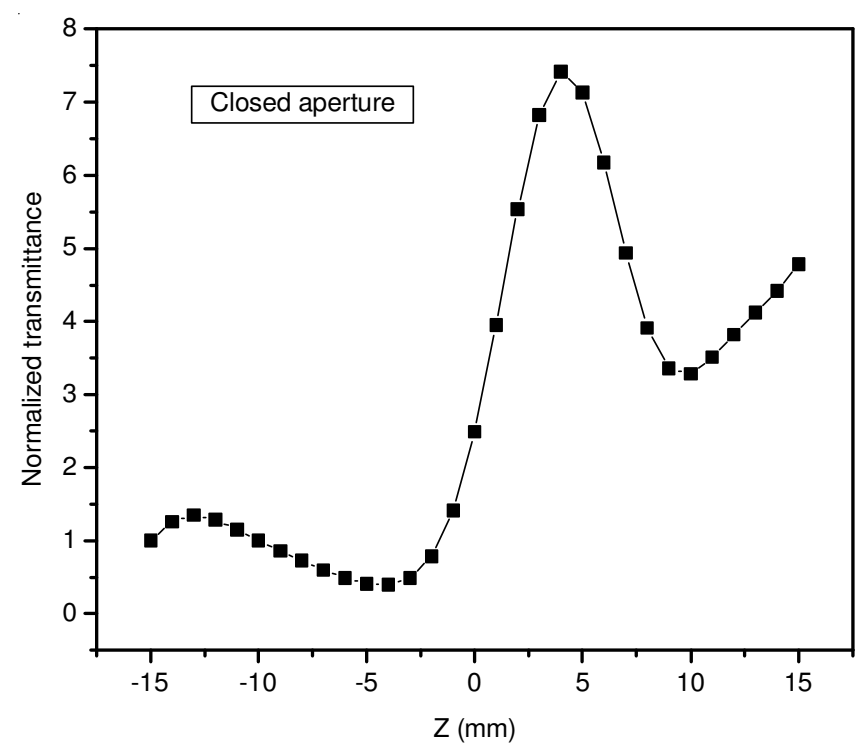

Fig. 12. Z-scan curve of LL5SS in closed aperture

[22] The large molecular polarizability of the material is responsible for high value of $\chi^{(3)}$ in the LL5SS crystal and is attributed to the $\pi$ electron cloud movement from donor to acceptor levels [23,24].

This may be an advantage for the application in protection of optical sensors. Some of the third order non-linear parameters are tabulated in the Table-5.

TABLE-5

THIRD ORDER NON-LINEAR OPTICAL PARAMETER OF LL5SS

\begin{tabular}{ll}
\hline Laser beam wavelength $(\lambda)(\mathrm{nm})$ & 640 \\
Lens focal length $(\mathrm{f})(\mathrm{cm})$ & 30 \\
Optical path distance $(\mathrm{Z})(\mathrm{cm})$ & 85 \\
Spot-size diameter in front of aperture $\left(\omega_{\mathrm{a}}\right)(\mathrm{cm})$ & 3.3 \\
Aperture radius $(\mathrm{ra})(\mathrm{mm})$ & 2 \\
Effective thickness $\left(\mathrm{L}_{\mathrm{eff}}\right)(\mathrm{mm})$ & $5.208 \times 10^{-2}$ \\
Non-linear refractive index $\left(\mathrm{n}_{2}\right)\left(\mathrm{cm}^{2} / \mathrm{W}\right)$ & $1.433 \times 10^{-12}$ \\
Non-linear absorption coefficient $(\beta)(\mathrm{cm} / \mathrm{W})$ & $2.4215 \times 10^{-6}$ \\
Absolute susceptibility $\left|\chi^{(3)}\right|$ esu & $5.326172 \times 10^{-10}$ \\
\hline
\end{tabular}

Micro hardness studies: Hardness measures the resistance of a sample to material deformation due to a constant compression load from a object and extremely important as far as the fabrication of devices is concerned. The high quality of the polishing material significantly improves the hardness values [25]. The hardness number $\left(\mathrm{H}_{\mathrm{V}}\right)$ is determined by the load over the surface area of the indentation and not the area normal to the force and is therefore not pressure. The hardness number of the grown crystal is calculated by using the following expression:

$$
\mathrm{H}_{\mathrm{V}}=1.8554\left(\frac{\mathrm{P}}{\mathrm{d}^{2}}\right)\left(\mathrm{kg} / \mathrm{mm}^{2}\right)
$$

where $\mathrm{P}$ is the applied load in $\mathrm{kg}$, $\mathrm{d}$ is the average length of indented impressions in $\mathrm{mm}$ and 1.8544 is a constant of geometrical factor for the diamond pyramidal indenter. The plot of $\mathrm{H}_{\mathrm{v}}$ versus $\mathrm{P}$ is shown in the Fig. 13. From the plot, the hardness number increases with the applied load and that satisfies the reverse indentation size effect (RISE). The plot $\log (\mathrm{P})$ versus $\log (\mathrm{d})$ is shown in Fig. 14 and using this plot 


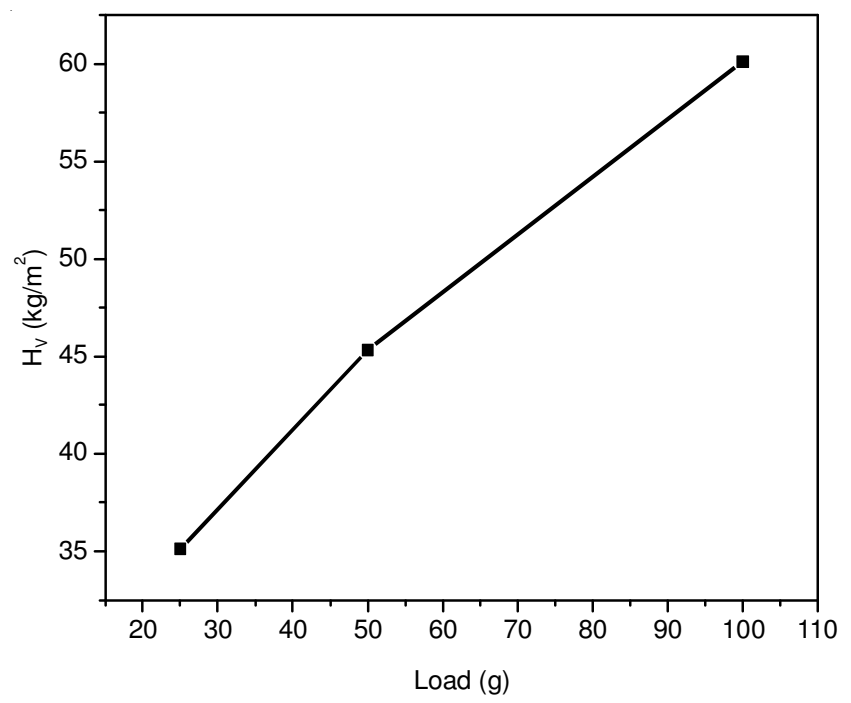

Fig. 13. Dependence of microhardness $\left(\mathrm{H}_{\mathrm{v}}\right)$ on applied indentation load $\mathrm{P}$ of LL5SS crystal

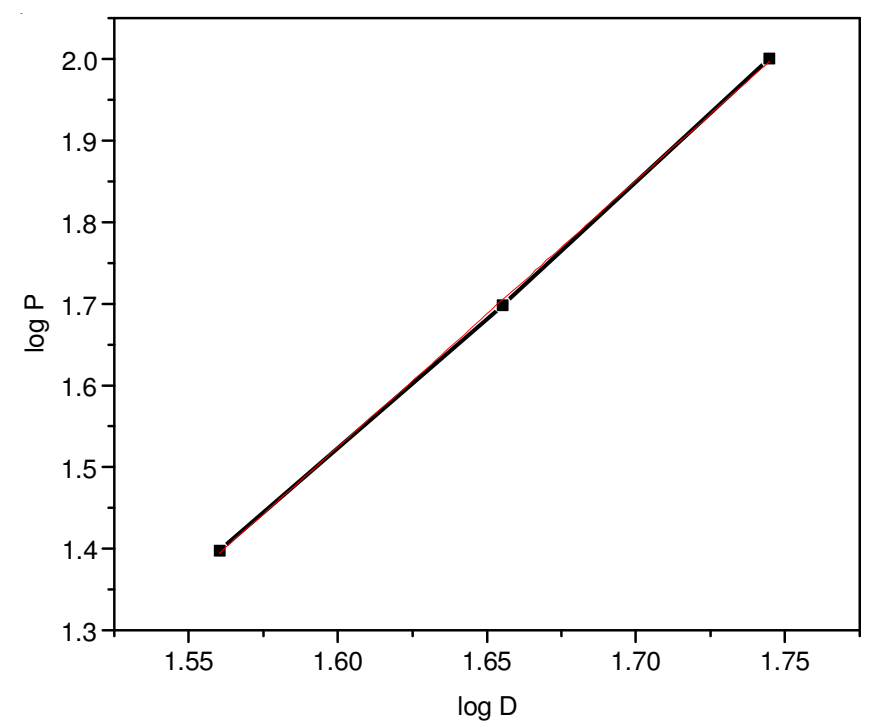

Fig. 14. Plot of $\log \mathrm{D}$ versus $\log \mathrm{P}$ of LL5SS crystal

the value of work hardening coefficient $\mathrm{n}$ was estimated. The $\mathrm{n}$ value was 3.26 which confirm that LL5SS crystal belongs to the soft material category. The elastic stiffness constant $\left(\mathrm{C}_{11}\right)$ for different loads (Fig. 15) calculated using Wooster's empirical formula:

$$
\mathrm{C}_{11}=\mathrm{H}_{\mathrm{v}}^{7 / 4}
$$

The calculation of stiffness constant shows that the binding forces between the ions are strong.

The resistance to fracture indicates the toughness of a material $\mathrm{K}_{\mathrm{c}}$ and is given by a relation:

$$
\mathrm{K}_{\mathrm{C}}=\frac{\mathrm{P}}{\beta_{0} 1^{3 / 2}}, 1 \geq \frac{\mathrm{d}}{2}
$$

where $\beta_{0}$ is the indenter constant, equal to 7 for the Vicker's diamond pyramid indenter.

Brittleness affects the mechanical behaviour of a material and gives information about the fracture induced in a material. Brittleness index $\left(\mathrm{B}_{\mathrm{i}}\right)$ is calculated using relation:

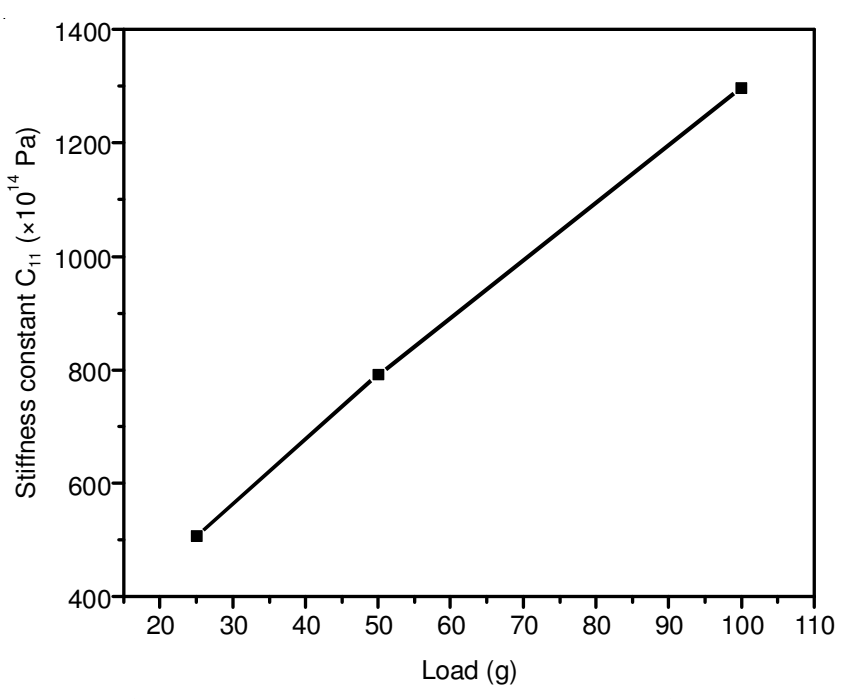

Fig. 15. Plot of load P versus stiffness constant of LL5SS crystal

$$
\text { Brittleness index }\left(\mathrm{B}_{\mathrm{i}}\right)=\frac{\mathrm{H}_{\mathrm{V}}}{\mathrm{K}_{\mathrm{C}}}
$$

The value hardness number $\left(\mathrm{H}_{\mathrm{V}}\right)$, Stiffness constant $\left(\mathrm{C}_{11}\right)$ and Brittleness index $\left(\mathrm{B}_{\mathrm{i}}\right)$ of LLSS was shown in the Table- 6 .

\begin{tabular}{ccccc}
\multicolumn{5}{c}{ TABLE-6 } \\
MECHANICAL PARAMETERS OF LL5SS CRYSTAL
\end{tabular}

Laser damage threshold (LDT) measurement: One of the important criteria for a NLO crystal to progress as a photonic device is its resistance to laser damage, since high optical intensities are involved in non-linear processes. The laser induced breakdown in the crystals caused by various physical processes such as multi photon absorption and electron avalanche for the transparent materials. A fundamental wavelength of 1064 $\mathrm{nm}$ Gaussian beam of pulse width $6 \mathrm{~ns}$ with a repetition rate of $10 \mathrm{~Hz}$ and was used to measure the laser damage threshold of LL5SS crystal. Laser damage threshold of the crystal was estimated using the relation:

$$
\text { Power density }\left(\mathrm{P}_{\mathrm{d}}\right)=\frac{\mathrm{E}}{\tau \mathrm{A}}
$$

where $A=\pi r^{2}, E$ is the input energy $(\mathrm{mJ}), \tau$ is the pulse width (ns) and $\mathrm{r}$ is the radius of the spot $(\mathrm{mm})$. The calculated values of the LDT of $5.6 \mathrm{GW} / \mathrm{cm}^{2}$. Good value of LDT indicates that a grown crystal contains a low defect and it can be used for device fabrication.

\section{Conclusion}

Single crystals of LL5SS were grown in aqueous solution using slow evaporation method. Single crystal X-ray analysis confirms that the crystals belong to the monoclinic system with space group $\mathrm{P} 2{ }_{1}$. The various functional groups were confirmed by FTIR analysis. Optical assessment showed that it has UV-Visible absorption cut off at around $324 \mathrm{~nm}$ the 
optical band gap energy is $3.536 \mathrm{eV}$ calculated by Tauc's Plot. The photoluminescence of LL5SS single crystal has maximum intensity at $432 \mathrm{~nm}$, which corresponds to violet emission. Dielectric studies show that the sample has low loss factor. Thermo gravimetric analysis showed the different decomposition stages. The SHG of LL5SS was confirmed by green light emission. The non-linear refractive index, absorption coefficient and third order susceptibility were found to be $1.433 \times$ $10^{-12} \mathrm{~cm}^{2} / \mathrm{W}, 2.4215 \times 10^{-6} \mathrm{~cm} / \mathrm{W}$ and $5.326172 \times 10^{-10} \mathrm{esu}$, respectively. Vickers micro hardness test showed that the grown crystal belongs to soft material category. The laser damage threshold power density for the grown crystal is $5.6 \mathrm{GW} \mathrm{cm}^{-2}$. All these studies indicates that the grown crystal possess good optical as well as mechanical properties towards the materials suitability for optical device fabrications.

Supplementary: CCDC: 1562492 contains the supplementary crystallographic data for the compound reported in this Article.

\section{ACKNOWLEDGEMENTS}

One of the authors (D. Jayalakshmi) is grateful to University Grants Commission, New Delhi, India for the support under minor research project scheme (No. F: MRP-5576/15(SERO/ UGC) dated January 2015).

\section{REFERENCES}

1. J. Zyss, Molecular Non-Linear Optics, Academic Press, Boston (1994).

2. D.R. Yuan, D. Xu, N. Zhang, M.G. Liu and M.H. Jiang, Chin. Phys. Lett., 13, 841 (1996) https://doi.org/10.1088/0256-307X/13/11/011.

3. I. Ledoux, Synth. Met., 54, 123 (1993); https://doi.org/10.1016/0379-6779(93)91051-3.

4. H.A. Petrosyan, H.A. Karapetyan, M.Y. Antipin and A.M. Petrosyan, J. Cryst. Growth, 275, 1919 (2005); https://doi.org/10.1016/j.jcrysgro.2004.11.258.

5. H.O. Marcy, L.A. DeLoach, J.-H. Liao, M.G. Kanatzidis, S.P. Velsko, M.J. Rosker, L.F. Warren, C.A. Ebbers, P.H. Cunningham and C.A. Thomas, Opt. Lett., 20, 252 (1995); https://doi.org/10.1364/OL.20.000252.

6. S.R. Marder, J.E. Sohn and G.D. Stucky, Materials for Non-linear Optics, ACS Symposium Series, p. 455 (1991)

7. S.S. Gupte, A. Marcano O, R.D. Pradhan, C.F. Desai and N. Melikechi, J. Appl. Phys., 89, 4939 (2001); https://doi.org/10.1063/1.1358325.
8. D. Arthi, E. Ilango, M. Mercina, D. Jayaraman and V. Joseph, J. Mol. Struct., 1127, 156 (2017); https://doi.org/10.1016/j.molstruc.2016.07.030.

9. K. Ramya, N.T. Saraswathi and C.R. Raja, Opt. Laser Technol., 90, 222 (2017); https://doi.org/10.1016/i.optlastec.2016.12.002.

10. N. Rani, N. Vijayan, K. Thukral, K.K. Maurya, G. Bhagavannarayana, D. Haranath, S. Verma and M.A. Wahab, Spectrochim. Acta A Mol. Biomol. Spectrosc., 105, 192 (2013); https://doi.org/10.1016/j.saa.2012.12.030.

11. V.S. Shankar, R. Sankar, R. Siddheswaran, R. Jayavel and P. Murugakoothan, Mater. Chem. Phys., 109, 119 (2008); https://doi.org/10.1016/j.matchemphys.2007.11.008.

12. J.-F. Ma, J. Yang, Li, S.-Y. Song, H.-J. Zhang, H.-S. Wang and K.-Y. Yang, Cryst. Growth Des., 5, 807 (2005); https://doi.org/10.1021/cg049723a.

13. A. Cote and G.K.H. Shimizu, Coord. Chem. Rev., 245, 49 (2003); https://doi.org/10.1016/S0010-8545(03)00033-X.

14. O.M. Yaghi, C.E. Davis, G. Li and H. Li, J. Am. Chem. Soc., 119, 2861 (1997); https://doi.org/10.1021/ja9639473.

15. C. Swiegers and T. Malefetse, Chem. Rev., 100, 3483 (2000); https://doi.org/10.1021/cr990110s.

16. S.A.M.B. Dhas and S. Natarajan, Cryst. Res. Technol., 43, 869 (2008); https://doi.org/10.1002/crat.200711152.

17. L. Kumari and W.Z. Li, Cryst. Res. Technol., 45, 311 (2010); https://doi.org/10.1002/crat.200900600

18. M. Jose, R. Uthrakumar, A.J. Rajendran and S.J. Das, Spectrochim. Acta Part A: Mol. Biomol. Spectrosc., 86, 495 (2012); https://doi.org/10.1016/i.saa.2011.11.002.

19. A. Aravindan, P. Srinivasan, N. Vijayan, R.G. Krishnan and P. Ramasamy, Spectrochim. Acta Part A: Mol. Biomol. Spectrosc., 71, 297 (2008); https://doi.org/10.1016/j.saa.2007.12.023.

20. M. Roman and W.T. Winter, Biomacromolecules, 5, 1671 (2004); https://doi.org/10.1021/bm034519+.

21. R.R. Babu, K. Sethuraman, N. Vijayan, G. Bhagavannarayana, R. Gopalakrishnan and P. Ramasamy, Cryst. Res. Technol., 41, 906 (2006); https://doi.org/10.1002/crat.200510693.

22. T.H. Wei, D.J. Hagan, M.J. Sence, E.W. Van Stryland, J.W. Perry and D.R. Coulter, Appl. Phys. B, 54, 46 (1992); https://doi.org/10.1007/BF00331733.

23. A.J. Kiran, D. Udayakumar, K. Chandrasekharan, A.V. Adhikari and H.D. Shashikala, J. Phys. At. Mol. Opt. Phys., 39, 3747 (2006); https://doi.org/10.1088/0953-4075/39/18/005.

24. C. He, Y. Wu, G. Shi, W. Duan, W. Song and Y. Song, Org. Electron., 8, 198 (2007) https://doi.org/10.1016/j.orgel.2007.01.002.

25. N. Sivakumar and G. Anbalagan, Opt. Mater., 60, 533 (2016); https://doi.org/10.1016/j.optmat.2016.09.010. 